\title{
A Retrospective Review of a Single-Center Experience with Posterolateral Fundoplication During Esophagogastrostomy After Proximal Gastrectomy
}

\author{
Masaki Aizawa, MD, PhD ${ }^{1} \cdot$ Hiroshi Yabusaki ${ }^{1} \cdot$ Koji Nakada $^{2} \cdot$ Atsushi Matsuki $^{1} \cdot$ Takeo Bamba $^{1} \cdot$ Satoru Nakagawa $^{1}$
}

Received: 6 December 2020 / Accepted: 22 May 2021 / Published online: 8 July 2021

(C) 2021 The Author(s)

Keywords Proximal gastrectomy · Esophagogastrostomy · Post-gastrectomy syndrome · Quality of life · Reflux esophagitis · Fundoplication

\section{Introduction}

For patients with proximal gastric cancer (PGC), proximal gastrectomy (PG) has been proposed as a surgical option with the expectation of ameliorating postgastrectomy syndrome. Although esophagogastrostomy with a large remnant stomach is a simple reconstruction method that allows gastric functions and capacity to accommodate food to be preserved, patients undergoing this procedure often develop severe reflux esophagitis. 1,2 At present, esophagogastrostomy with an additional antireflux procedure is considered as the most promising reconstruction technique. ${ }^{3-5}$ Herein, we report our experience with the addition of the posterolateral

Masaki Aizawa, MD, $\mathrm{PhD}$

maizawa@niigata-cc.jp

Hiroshi Yabusaki

yabu@niigata-cc.jp

Koji Nakada

nakada@jikei.ac.jp

Atsushi Matsuki

matsukia@niigata-cc.jp

Takeo Bamba

ban@niigata-cc.jp

Satoru Nakagawa

satoru-n@niigata-cc.jp

1 Department of Digestive surgery, Niigata Cancer Center Hospital, 2-15-3, Kawagishicho, Niigata 951-8566, Japan

2 Department of Laboratory Medicine, The Jikei University School of Medicine, 3-25-8, Nishishimbashi, Minato-ku, Tokyo 105-8461, Japan fundoplication (PLF) technique to the standard esophagogastric anastomosis.

\section{Methods}

The schema of PLF is shown in Fig. 1a. After PG with D1+ regional lymphadenectomy, esophagogastrostomy using a mechanical circular stapler was performed at the anterior wall of the remnant stomach, the center of which was up to a length of $40 \mathrm{~mm}$ from the cut end of the stomach. Then, the cut end of the stomach was fixed to both the top posterior end of the freed esophageal wall and the diaphragm. Finally, the posterior half-circumference of the esophagus was wrapped with the anterior gastric wall by placing stay sutures.

After obtaining approval from the ethics board for this study, the data of 28 patients who underwent PLF between July 2016 and December 2019 was reviewed.

\section{Results}

The clinicopathological features and postoperative findings are summarized in Table 1. The surgery was performed by the laparoscopic approach in 23 patients. Seven patients developed benign membranous stricture several months after surgery, all of the seven patients were successfully treated by endoscopic mechanical dilatation. The PLF was maintained during over years (Fig. 1b-d). None of the patients developed either endoscopic or clinical evidence of reflux esophagitis. 

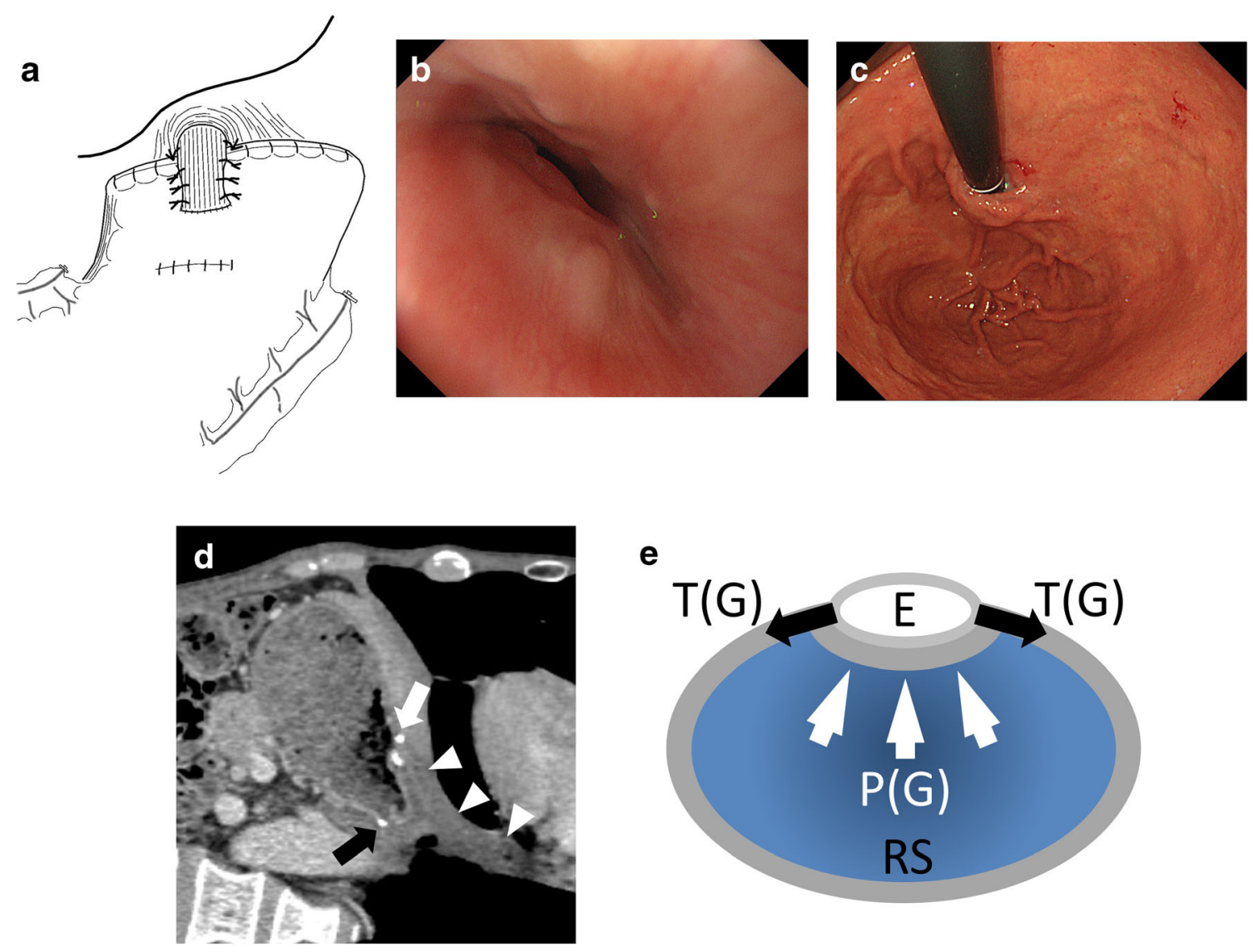

Fig. 1 Schema of posterolateral fundoplication after esophagogastrostomy (a), endoscopic view the of anastomosis from the esophagus (b) and stomach (c) at the 3-years follow-up after surgery, longitudinal-section CT image at the 3-year follow-up after surgery $(\mathbf{d})$, white arrow: anastomosis, black arrow: gastric stump, white arrowhead:

\section{Discussion}

The PLF procedure is simple. The proposed physiology underlying the antireflux effect of PLF is shown in Fig. 1e. The $180^{\circ}$ wrapping of the esophagus with the anterior gastric wall forms the internal valve. Furthermore, the stretch of the gastric wall pulls the side wall of the esophagus on either side in the lateral direction. While the remnant stomach becomes filled with contents, the lumen of the esophagus closes, and does not open until the remnant stomach becomes empty.

Though the safety of PLF was acceptable, development of anastomotic stenosis was the lone worrisome event. Stenosis developing after mechanical esophagogastrostomy has been reported to be not life-threatening and as being treatable by mechanical dilatation. ${ }^{6}$

Patients in whom the entire abdominal esophagus and more than half of the stomach can be preserved are a suitable indication of PLF. In regard to the oncological safety, the noninferiority of $P G$ to total gastrectomy remains to be established. Hence, in Japan, the indication of PG for patients

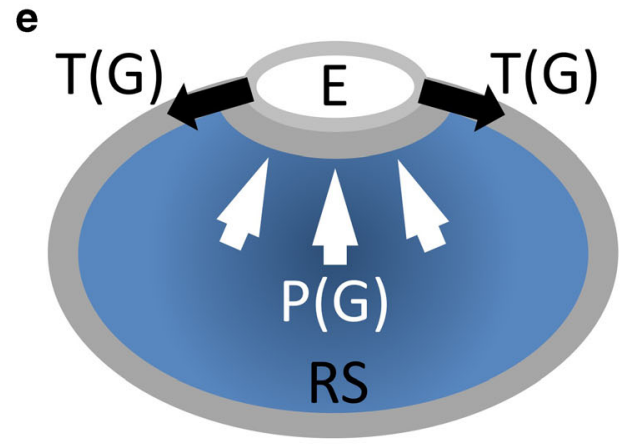

esophagus, Coronal-section image of the abdominal esophagus overlapping the remnant stomach and mechanical actions (e), E: esophagus; RS: remnant stomach; $\mathrm{P}(\mathrm{G})$ : internal pressure of the remnant stomach; $\mathrm{T}(\mathrm{G})$ : traction by stretching of the stomach

with PGC is generally limited to patients with clinical stage T1N0 disease.

There were limitations of the present study. First, this was a retrospective study with a small sample size. Second, supportive evidence to validate the rationale for PLF is still lacking. Third, a comparison of different antireflux procedures is needed to establish the optimal antireflux procedure.

\section{Conclusion}

Esophagogastrostomy with PLF is a promising reconstruction procedure after PG.

Author contribution Substantial contribution to the conception of this work and drafting of this manuscript: Masaki Aizawa

Acquisition and analysis of data: Atsushi Matsuki and Takeo Bamba

Critical revision of the work for important intellectual content: Hiroshi Yabusaki, Koji Nakada, and Satoru Nakagawa 
Table 1 Patient characteristics, tumor-related factors and surgical outcome

\begin{tabular}{|c|c|c|}
\hline \multicolumn{2}{|l|}{ Characteristics } & \multirow{2}{*}{$\begin{array}{l}\text { Total } \mathrm{N}=28 \\
69.1(8.81)\end{array}$} \\
\hline Age (year) & Mean (SD) & \\
\hline \multirow[t]{2}{*}{ Gender, N (\%) } & Male & $26(92.9)$ \\
\hline & Female & $2(7.1)$ \\
\hline \multirow[t]{3}{*}{ Disease, N (\%) } & Adenocarcinoma & $27(96.4)$ \\
\hline & NEC & $1(3.6)$ \\
\hline & GIST & $0(0)$ \\
\hline Body mass index & Mean (SD) & $23.5(3.26)$ \\
\hline \multirow[t]{4}{*}{ Pathological T stage, N (\%) } & $1 \mathrm{a}$ & $5(17.9)$ \\
\hline & $1 b$ & $19(67.8)$ \\
\hline & 2 & $3(10.7)$ \\
\hline & 3 & $1(3.6)$ \\
\hline \multirow[t]{3}{*}{ Pathological N stage, N (\%) } & 0 & $25(89.2)$ \\
\hline & 1 & $2(7.2)$ \\
\hline & 2 & $1(3.6)$ \\
\hline Pathological stage, & IA & $23(82.1)$ \\
\hline \multirow[t]{3}{*}{$\mathrm{N}(\%)$} & IB & $3(10.7)$ \\
\hline & IIA & $0(0.0)$ \\
\hline & IIB & $2(7.2)$ \\
\hline \multirow[t]{2}{*}{ Surgical approach, N (\%) } & Open method & $5(17.9)$ \\
\hline & Laparoscopic & $23(82.1)$ \\
\hline Operation time (min) & Median (range) & $296(215-406)$ \\
\hline Blood loss during surgery & Median (range) & $25(3-800)$ \\
\hline Postoperative morbidity & None & $21(75.0)$ \\
\hline ( $\geq$ Clavien-Dindo grade III), N (\%) & Anastomotic stenosis & $7(25.0)$ \\
\hline Body weight loss a year after surgery, $\%$ & Mean (SD) & $-10.7(6.6)$ \\
\hline Period of hospital stay after surgery (date) & Median (range) & $9(7-22)$ \\
\hline Endoscopic evidence of esophagitis, N (\%) & Any grade of LA classification & $0(0)$ \\
\hline \multirow[t]{2}{*}{ Reflux symptom after surgery } & - & $28(100)$ \\
\hline & + & $0(0.0)$ \\
\hline \multirow[t]{2}{*}{ Recurrence after surgery } & - & $28(100)$ \\
\hline & + & $0(0.0)$ \\
\hline Observation period, month & Median (range) & $22.5(12.0-43.4)$ \\
\hline
\end{tabular}

$N E C$, Neuroendocrine carcinoma; GIST, Gastrointestinal stromal tumor; LA, Los Angeles
All authors agree to be accountable for all aspects of the work and to ensure that questions related to the accuracy and integrity of any part of the work have been appropriately investigated and resolved.

\section{Declarations}

Ethics approval and consent to participate All procedures followed were in accordance with the ethical standards of the responsible committee on human experimentation (institutional and national) and with the Helsinki Declaration of 1964 and later versions. The study was conducted with the approval of our Institutional Review Board.

Sex-inclusive reporting

The subjects' sex was not considered as a biologic variable in this work.
Conflict of interest The authors have no conflicts of interests to declare.

Open Access This article is licensed under a Creative Commons Attribution 4.0 International License, which permits use, sharing, adaptation, distribution and reproduction in any medium or format, as long as you give appropriate credit to the original author(s) and the source, provide a link to the Creative Commons licence, and indicate if changes were made. The images or other third party material in this article are included in the article's Creative Commons licence, unless indicated otherwise in a credit line to the material. If material is not included in the article's Creative Commons licence and your intended use is not permitted by statutory regulation or exceeds the permitted use, you will need to obtain permission directly from the copyright holder. To view a copy of this licence, visit http://creativecommons.org/licenses/by/4.0/. 


\section{References}

1. An JY, Youn HG, Choi MG, Noh JH, Sohn TS, Kim S. The difficult choice between total and proximal gastrectomy in proximal early gastric cancer. Am J Surg 2008;196:587-591.

2. Ronellenfitsch U, Najmeh S, Andalib A, Perera RM, Rousseau MC, Mulder DS, Ferri LE. Functional outcomes and quality of life after proximal gastrectomy with esophagogastrostomy using a narrow gastric conduit. Ann Surg Oncol 2015;22:772-779.

3. Inada T, Yoshida M, Ikeda M, Yumiba T, Matsumoto H, Takagane A, Kunisaki C, Fukushima R, Yabusaki H, Nakada K. Evaluation of QOL after proximal gastrectomy using a newly developed assessment scale (PGSAS-45). World J Surg 2014;38:3152-3162.
4. Kuroda S, Nishizaki M, Kikuchi S, Noma K, Tanabe S, Kagawa S, Shirakawa Y, Fujiwara T. Double-Flap Technique as an Antireflux Procedure in Esophagogastrostomy after Proximal Gastrectomy. J Am Coll Surg 2016;223:e7-e13.

5. Yamashita Y, Yamamoto A, Tamamori Y, Yoshii M, Nishiguchi Y. Side overlap esophagogastrostomy to prevent reflux after proximal gastrectomy. Gastric Cancer 2016;20:728-735.

6. Yuan Y, Wang KN, Chen LQ. Esophageal anastomosis. Dis Esophagus 2015;28:127-137.

Publisher's Note Springer Nature remains neutral with regard to jurisdictional claims in published maps and institutional affiliations. 